\title{
Study on the Transformation and Upgrading of Suburban Tourism in Xinjin County, Chengdu City
}

\author{
Ge He \\ Management school of Sichuan agricultural university \\ Chengdu, China, 611130
}

\begin{abstract}
This paper aims at putting forward policy recommendations after current situations and issues of the transformation and upgrading of suburban tourism are analyzed in Xinjin County. The results find single industry and imperfect function, tourism products homogeneity with no rural flavor, backward marketing methods and inadequate market development are the issues. To promote it, the government should: (1) enrich and optimize the structure of tourism products; (2) enrich single industry and imperfect function; (3) improve tourism marketing mode; (4) increase investment in tourism and strengthen the training and introduction of talents.
\end{abstract}

Keywords-suburban tourism; transformation and upgrading; Xinjin County

\section{INTRODUCTION}

As a new industry form, suburban tourism has grown rapidly with China's social and economic development. it not only provides a good place for leisure and entertainment for urban dwellers, but also effectively increases farmers' employment and income. Xinjin County, located in the southern suburb of Chengdu city, is an important destination for short-term holiday tourism. The last 40 years saw suburban tourism has experienced transformation and upgrading in Xinjin County. However, it has also been confronted with some issues. The existing literature has done a lot of research on the topic of transformation and upgrading of suburban tourism, but there is little literature reported about that of Xinjin County. Therefore, this paper aims at analyzing the current situations and revealing the existing issues of transformation and upgrading of suburban tourism in Xinjin County and putting forward policy recommendations. This paper unfolds as follows: section II introduce some viewpoints of the similar topics by literature review. Section III analyzing the current situations of transformation and upgrading of suburban tourism in Xinjin County. Section IV explores the main issues of that. The last section puts forward some policy recommendations.

\section{LITERATURE REVIEW}

The last 40 years saw the research on suburban tourism has become a hot topic with the rapid development of that. Recently, to realize the transformation and upgrading of suburban tourism has become a focus subject with the change of people's needs. Many scholars have made useful explorations on that and many achievements have been made.

This paper is funded by Chengdu Municipal Soft Science 2016 and 2018 Project (No.2015-RK00-00176-ZF; 2017- RK00-00182-ZF), Sichuan provincial Soft Science 2018 Project (No.18RKX0774).
Such as, Zou(2014) proposed a community-driven development mode of rural tourism and illustrated three principles of that: localization of supply chain, communityexternal investor symbiosis, and democratization of decision making. Dai(2016) found that diversifying the tourism products and improving marketing coverage are two approaches that are favoured by both the local service providers and the tourists. However, different concerns are revealed for other approaches, such as improving service quality, increasing accommodation capacity and providing collective tourism activities. Mcareavey (2011) revealed four themes: institutional (in)capacity, legitimacy of local groups, navigating between stakeholder interests and sustainable tourism in practice, which are the potential for sustainable rural tourism to contribute to rural development . Skuras (2010) analyzed the expenditure behavior of 465 tourists in two rural and lagging areas of Greece and concluded that the tourism experience is significantly and positively affected by the income, the source from which information about the trip is retrieved (Internet, newspapers as well as general press and special travel press) and by the amount of information sought by the consumer prior to the trip. In turn, the quality of the tourism experience is the major endogenous factor that positively influences expenditures for rural tourism. However, there is few results of that in Xinjin County. For this reason, this paper is aimed at analyzing the current situations of the transformation and updating of suburban tourism in Xinjin County ,Chengdu city and revealing the existing issues then some policy recommendations are put forth.

\section{ANALYSIS ON CURRENT SITUATION OF THE TRANSFORMATION AND UPGRADING OF SUBURBAN TOURISM IN XINJIN COUNTY}

\section{A. Rapid development of leisure agriculture promotes full improvement of suburban tourism}

Since 2010, Xinjin County has continuously nurtured and strengthened tourism, and strived to improve the development mode of suburban tourism by means of leisure fishing, leisure farms and folk villages. Xinjin County has gradually upgraded the suburban tourism industry from fund support, management systems improvement and profession standard formulation. Suburban tourism with leisure agriculture as the focus has developed rapidly. This not only promotes the integration of the first, second and third industries in rural areas, but also effectively promotes the high-quality development of tourism in the whole county. As a result, the county's tourism income 
increased by more than $26 \%$ annually from 2012 to 2014 . The proportion of tourism added value in GDP is 6.8 percentage points higher than the average level of Sichuan Province, and the proportion of tourism added value in service industry is 21.3 percentage points higher than the average level of Sichuan Province. Farmers' income from tourism development is higher than the average level of 7.9 percentage points in the whole province. Among the employees, the proportion of farmers is as high as 60\%. In 2015, the county received 12 million tourists and realized 2.63 billion Yuan in tourism revenue, which increased by $33.3 \%$ and $26.4 \%$ respectively over the same period last year. Tourism income accounted for $11 \%$ of the county's GDP.

\section{B. Diversify tourism products}

Xinjin County has large-scale, high-quality leisure tourism scenic spots, such as Laojun mountain, Lihua Valley and so on. Agritainment, as the most important mode of traditional rural tourism, has taken the advantages of these scenic spots with its own location, food flavor and other characteristics exploited. Combined with the requirements of the layout of new rural construction planning, the Agritainments strived to transform their style and environment and keep harmony with its environment. By this way, traditional agritainment have been realized their transformation and upgrading. Because of the low cost and the obvious demonstration, the transformation and upgrading of suburban tourism not only optimized the rural ecology, living and production environment, but also effectively solved the rural social problems such as local farmers' employment and entrepreneurship, and promoted the rapid development of rural economy and farmers' income. Additionally, various suburban tourism products such as characteristic rural tourism, agricultural leisure tourism, agricultural experience and rural folk cultural activities, rural landscape scenic spots have been developed in large quantities, and regional tourism brands such as fish hotpot, pear blossom festival have gradually been formed.

\section{Multi-Point and multi-pole spatial layout been formed}

Based on the distribution of agricultural resources, the planting industry in Xinjin County is divided into large-scale grain planting area in the west, vegetable industry demonstration area in the north, fruit planting area in the southwest and southeast. Xinjin County combines the allocation of tourism resources with the distribution of agricultural resources and tries to make them consistent. Meanwhile, the local government intentionally guided the formation of suburban tourism resources with certain advantages, such as Hua Wu Ren Jian. Driven by these advantageous tourism resources, some traditional tourist attractions have been gradually optimized and perfected, a unique core of suburban tourism were eventually developed . With these core points extended, a regional group-type suburban tourism circle has gradually been formed. In short, the suburban tourism in Xinjin County has shown a multipoint and multi-level development trend, which is not only consistent with the distribution of agricultural resources, but also shows the group development around the main landscape resources.

\section{Great development potential in suburban tourism}

Xinjin County is connected with Shuangliu County in the east, Qionglai County in the west, Dayi County in the south, Pengshan County in the South and Chongzhou County in the north so it has superior location. Moreover, according to the Chengdu Urban Master Plan (2016-2035), Xinjin has been listed as one of the six major development corridors. There are eight provincial highways such as the Second Circumferential Highway in Chengdu. And Beijing-Kunming Expressway, Xiamen-Chengdu Expressway, Chengxinpu Expressway go directly to the city center. About 2020, Xinjin County will be directly connected with the rest part of Chengdu through the subway. All these have laid a solid foundation for Xinjin county to develop suburban tourism. Besides Xinjin County has a unique climate, with no severe cold in winter and no intensive hot in summer. It is rich in water resources so it has dense water network. After convergence of Jinma River, Xihe River, Nanhe River, Yangma River and Yangliu River, it flows into Minjiang River. And Xinjin County is rich in forest resources, which also provides natural resources advantages for developing suburban tourism. In recent years, Xinjin County has made full use of the advantages of domestic water resources and developed various wetlands rationally, forming a unique water city of Xinjin. Moreover, guided by delicate ecological agriculture, Xinjin County has gradually expanded in the fields of aquatic products, vegetables, flowers and fruits. On the basis of the original human landscape, waterscape landscape, biological landscape, ruins, tourist commodities, cultural and folk customs and other tourism resources, Xinjin County has developed into an important tourist destination in Western Sichuan.

\section{ISSUES OF TRANSFORMATION AND UPGRADING OF SUBURBAN TOURISM IN XINJIN COUNTY}

\section{A. Single industry and imperfect function}

Generally speaking, suburban tourism industry in Xinjin county has been relatively single and its function is imperfect. At present, suburban tourism industry in Xinjin County is mainly concentrated in Yongshang, Jiulian, Xingyi, Anxi. Tourism activities have been involved in fishing, flower appreciation, farming experience ,which is absolutely carried by tourist resorts, fishermen's entertainment, farmer's entertainment, leisure villas and so on. On one hand, the operators are still mainly individual farmers. On the other hand, the above-mentioned tourist destinations were mainly around large-scale tourist attractions with relatively centralized but separate operator patterns have been formed. These have led to suburban tourisms were confronted to meet the needs of traditional tourism for food and accommodation, while its modern roles such as education, leisure, sports are difficult to play. Such as Lihua valley, as an important tourist resort, there are many Agritainments which are managed by individual farmer households. Moreover, they all mainly rely on the Pear Flower Festival to attract tourists. The management mode is highly consistent, which makes it difficult to play a modem tourism role. 


\section{B. Tourism products homogeneity with no rural flavor}

The structure of tourism products is single. The existing suburban tourism products in Xinjin County are closely combined with local agricultural products such as grapes, river fish, grain and oil, organic vegetables with geographical indications such as Huang-la-ding, Minjiang Jiu-huang have been formed. Objectively speaking, the variety of tourism products is relatively single and the homogeneity of tourism products is serious. Those made the transformation and upgrading of suburban tourism difficult to effectively implement. Moreover, tourism product design is rough and is short of local rural flavor. Most design of suburban tourism products were originated from other tourist destinations or improved slightly while the development of agricultural products into tourism products is still at the primary stage with few humanistic flavor and cultural characteristics granted. Those led to inadequate innovation, inadequate connotation and insignificant characteristics of suburban tourism products. With Anxi Town, where hotpot is famous for its favor as an example, Tourists can only experience these services focused on the catering with few agricultural experience, interactive projects, leisure sports offered. Owing to being short of entertainment and novelty, it is difficult to attract people to participate in these tourism projects.

\section{Backward marketing methods}

First of all, because most of the suburban tourist attractions are operated by local farmer households or farmers' professional cooperatives. This means suburban tourism management is a decentralized mode, which not only lead to difficulty in forming the agglomeration effect but also make market cost greatly increased. Secondly, some operators of tourism are short of marketing awareness, and the local government's investment in tourism marketing is insufficient. The marketing mode of suburban tourism in Xinjin County is still very traditional, and the operators have not established stable cooperative relations with relevant travel agencies. The narrow marketing channels are difficult to meet the needs of information dissemination. Thirdly, in the case that mobile internet has gradually become the main media of suburban tourism marketing, there is no mobile phone application software for other scenic spots, such as Banzhulin, egret beach and citrus garden in Jiu-lian-cun, besides Lihua valley and HuaWuRenJian. Fourth, small amount of online marketing information and slow update of tourism information so the marketing of suburban tourism is short of tourism route recommendation, local food introduction, recent activities promotion. Finally, without subdividing the consumer market according to the preferences of different consumers in the market, a single marketing strategy is adopted for different age groups, different gender groups and different income levels, which cannot meet the needs of different consumers for tourism information.

\section{Inadequate market development}

Different regions, different ages, different occupations and different incomes all affect the demand of suburban tourism products. Providing different tourism products and service experience for different customers can not only meet the needs of different consumers, but also maximize the tourism market. However, field survey shows that in the process of transformation and upgrading of suburban tourism in Xinjin County, there is a lack of effective investigation on different consumer market demand. The structure of tourism products is also relatively single. This reduces the attractiveness of urban tourism to different consumers. Due to being short of investigation and subdivision of different consumer markets, The market demand and its changes cannot be grasped in time. This makes it difficult to attract local tourists continuously and develop foreign consumer market. On the other hand, most tourist attractions provide tourism services such as flower appreciation, fruit picking, fishing etc. For example, one of the main tourism items of Lihua valley is only spring flower appreciation, while entertainment, shopping, sports and their related services are less. In a word, the suburban tourism in Xinjin County mainly stayed in the primary service Without high-quality and high-service tourism products and markets, narrow and single tourism market structure, and being short of sustained and sufficient customers.

\section{Policy Recommendation For Promoting THE TRANSFORMATION AND UPGRADING OF SUBURBAN TOURISM IN XINJIN COUNTY}

\section{A. To enrich and optimize the structure of tourism products}

Firstly, Xinjin County should give priority to the development of suburban tourism industry and pay key support on it. Relevant departments, relevant industries and industry organizations should jointly participate in promoting the development of suburban tourism. It is necessary to develop recreational tourism in line with the social development trend of people's increasing attention to physical health and the increasingly serious aging. Xinjin County should explore folk culture and create rural folk tourism. The transformation and upgrading of tourism industry can be promoted by increasing tourism experience, Innovating Tourism forms and enhancing the attractiveness of tourism projects.single industry and imperfect function

Secondly, Xinjin County should strengthen industrial integration. On the one hand, it will integrate with the local folk traditional crafts and develop the tourism crafts industry with the characteristics of Xinjin folk traditional culture. The integration of tourism and creative industries should be also promoted. On the other hand, tourism should be combined with sports and folk customs. Deeply explore local folk activities and develop folk sports tourism items. Construction of greenways and mountaineering trails in qualified tourist attractions in order to developed of sports tourism products such as cycling and mountaineering. Finally, relying on the aquaculture industry in Anxi Town, the local government should hold sports events such as fishing competitions to attract tourists.

Thirdly, Xinjin County should improve the public service system for tourism. Perfect the infrastructure according to the standards of tourism lines. Increase public parking lots and toilets in scenic spots. Improve emergency facilities such as medical points and emergency shelters in scenic spots. In addition, in order to facilitate tourists, the dynamic monitoring 
system of scenic spots should be established to keep abreast of the real-time situation of scenic spots. At the same time, the local government should set up a self-service system to provide inquiries of tourism information and improve the matching tourist signs and scenic spots. Focusing on the elements of "eating, living, transportation, travel, shopping and entertainment", special tourist service centers should be established so that professional services should provide highquality services for tourists.

\section{B. To enrich single industry and imperfect function}

Xinjin County should increase humanistic and cultural tourism products, develop eco-protection tourism projects and enrich core tourism products, such as building eco-protection participation projects, self-driving experience camps, health recuperation bases, Buddhist and Taoist sites etc. It can also upgrade existing tourism projects to achieve tourism product innovation. For example, activities with European flavor should be held in Huayuan Town, which is rich in European architectural style. Kiwifruit harvesting competitions should be held in its producing areas, and food festivals should be held in Anxi Town, where aquatic food is unique and famous. According to market demand and different groups, we should develop and design tourism products with different characteristics to attract tourists with different preferences, such as eco-health tourism projects for elderly groups. At the same time, high-end products and low-end products ought to be distinguished to adapt to different market demands, which can also make the products of various scenic spots form certain differences to avoid homogenization.

\section{To improve tourism marketing mode}

Mobile Internet plays an irreplaceable role in the promotion of tourism products. Xinjin County should develop convenient and fast mobile phone application software to promote tourism resources by timely communication such as webchat, Weibo and short message. At the same time, corresponding tourist attractions website should be established to speed up the update and transmission of information Moreover, promotional tourism projects with certain influence and popularity ought to be paid more importance , such as Anxi Town, which is known as "China Fish head Hotpot Town" should improve its popularity, strengthen its brand influence so as to promote the development of the tourism industry for the whole Xinjin County by various means of network propaganda.

\section{To increase investment in tourism.}

Xinjin County should arrange special funds for tourism development as a whole. Policy support for key tourism projects in terms of land, credit and other aspects should be provided so as to ensure the sustainable development of tourism projects. New tourism projects with good potential should be introduced actively in line with the overall urban planning. The local government ought to provide financial subsidies for the construction of tourism infrastructure and improve the construction of its supporting facilities. In addition, Xinjin County should invest special funds in tourism brand building, tourism product marketing, and encourage enterprises to develop and produce tourism products with unique tourism characteristics and great social influence. conditions permitting, special stores for tourist goods in scenic spots should be set up. And incentive policies ought to be established to reward projects, enterprises, cooperatives and individuals that have made important contributions to tourism.

\section{E. To strengthen the training and introduction of talents}

Firstly, the local government ought to take a lead in introducing high-level tourism talents with high salaries and high salaries, inviting industry experts from famous universities and scientific research institutes at home and abroad to carry out targeted training courses and lectures; and setting up expert groups to provide decision-making advice, theoretical support and intellectual support for the development of suburban tourism industry in Xinjin county. Secondly, the local government should also vigorously introduce large-scale domestic and foreign tourism enterprises, high-end tourism talents by means of making financial subsidies, housing allocation, employment and enrollment arrangements for family members. Thirdly, the existing tourism stuffs ought to be received more training of professional skills such as the introduction of local characteristic tourism resources, the interpretation of "fish culture" in Anxi Town, the inheritance of religion and culture in LaoJunShan Temple, and the study of the modernization concept of tourism management and the cultivation of tourism service awareness so as to improve their quality. Finally, we should improve the evaluation system of the technical level of tourism practitioners and build up a team of employees adapted to different jobs. Through cooperation with universities with tourism-related majors and establishing training bases in the park, we can find and introduce excellent talents.

\section{CONCLUSION}

Xinjin county has experienced tansformation and upgrading of suburban tourism and made great achivements.However, it faces the following issues: (1) single industry and imperfect function; (2) tourism products homogeneity with no rural flavor;(3)backward marketing methods;(4)inadequate market development. To promote its transformation and upgrading, the local government ought to: (1) enrich and optimize the structure of tourism products; (2)enrich single industry and imperfect function; (3)improve tourism marketing mode; (4) increase investment in tourism and strengthen the training and introduction of talents.

\section{REFERENCES}

[1] Zou, T. , Huang, S. S., \& Ding, P., Toward a community-driven development model of rural tourism: the Chinese experience. International Journal of Tourism Research, 16(3), 261-271. 2014.

[2] Dai, L., Wan, L., Xu, B., \& Wu, B., How to improve rural tourism development in Chinese suburban villages? Empirical findings from a quantitative analysis of eight rural tourism destinations in Beijing. Area. 2016.

[3] Mcareavey, R., \& Mcdonagh, J., Sustainable rural tourism: lessons for rural development. Sociologia Ruralis, 51(2), 175-194. 2011. 
[4] Skuras, D., Petrou, A., \& Clark, G., Demand for rural tourism: the effects of quality and information. Agricultural Economics, 35(2), 183-
192. 2010. 